\title{
A cibersexualidade e a pesquisa online: algumas reflexões sobre o conceito de barebacking
}

Luís Augusto Vasconcelos da Silva ${ }^{1}$

SILVA, L.A.V. Cybersexuality and online research: some reflections about the concept of barebacking. Interface - Comunic., Saude, Educ., v.14, n.34, p.513-27, jul./set. 2010.

This paper results from online research on aspects of male sexuality and, more precisely, about male interactions within new contexts of the HIV/AIDS epidemic. It seeks to discuss the possibilities of the internet as a research field, considering the sociocultural issues that are opened up by new information technologies. This is the case of the practice of barebacking, which is generally defined as intentional unprotected anal sex. More specifically, this paper raises questions about some tensions and conceptual ambiguities of barebacking, especially regarding unprotected sex between steady partners and between casual partners, according to discussions developed by some users of orkut communities, within the Brazilian context. Finally, it is highlighted that the players who say that they are barebackers are not necessarily so, but neither do they understand the concept in the same way, which requires broader reflection about such communities' different users and contexts of use.

Keywords: Internet. Sexuality. Homosexuality male. Unsafe sex. Acquiride Immunodeficiency Syndrome. HIV.
Este artigo é decorrente de uma pesquisa online sobre aspectos da sexualidade masculina, mais precisamente sobre as interações masculinas em novos contextos da epidemia de HIV/Aids. Busca discutir as possibilidades da internet como campo de pesquisa, considerando os aspectos socioculturais abertos pelas novas tecnologias de informação. Este é o caso das práticas de barebacking, geralmente definido como sexo anal desprotegido de forma intencional. Mais especificamente, neste artigo, serão problematizadas algumas tensões e ambiguidades conceituais do barebacking, sobretudo no que diz respeito ao sexo desprotegido entre parceiros fixos e entre parceiros ocasionais, de acordo com a discussão desenvolvida por alguns usuários das comunidades do orkut, no contexto brasileiro. Finalmente, destaca-se que os atores que se dizem barebackers não são, necessariamente, mais os mesmos, tampouco entendem o conceito da mesma forma, o que exige uma reflexão mais ampla sobre seus distintos usuários e contextos de uso.

Palavras-chave: Internet. Sexualidade. Homossexualidade masculina. Sexo sem proteção. Síndrome de Imunodeficiência Adquirida. HIV.
${ }^{1}$ Universidade Federal da Bahia. PAF III - Rua Barão de Jeremoabo, $s / n$. Campus Universitário de Ondina, Salvador BA, Brasil. 40.170-115. luisvascon@uol.com.br 


\section{Introdução}

As novas referências de identidade deslocam-se em um período de aceleradas transformações, de excessos - superabundância factual, espacial e do indivíduo (Augé, 1994). Nesta direção, as novas tecnologias de informação, o ciberespaço, como um dispositivo de comunicação interativo e comunitário (Lévy, 1999), põem em evidência distintas perspectivas de interação social, redimensionando as fronteiras espaciais e produzindo novos discursos sobre a gestão e necessidade do corpo, sobre uma sexualidade experimentada como "pura imagem" (Le Breton, 2003, p.135).

À primeira vista, esse olhar 'sob a superfície' pode sugerir uma metamorfose incessante ou, em outras palavras, uma produção ilimitada de textos e signos, corpos virtuais. Entretanto, os corpos continuam, materialmente, interagindo com outros corpos (e outras máquinas), ao mesmo tempo em que são produzidos 'novos' discursos e concepções interativas - interações mediadas por signos e significados culturais.

A internet pode servir, portanto, como campo de produção textual, possibilitando a leitura de padrões e (novos) significados culturais. Em uma perspectiva geertziana, a internet possibilita a inscrição ou fixação de um discurso social, viabilizando uma atividade de interpretação dos significados socialmente disponíveis (Geertz, 1989). Nesse sentido, os 'contextos' online e offline encontram-se imbricados, na medida em que os signos que se deslocam na rede online dialogam com a vida social. As tecnologias de informação, portanto, não constituem um mundo "em si", pois são usadas por atores humanos, concretos, em contextos sociais específicos (Slater, 2002).

Nessa direção, o discurso midiático pode reproduzir padrões interativos e imagens valorizadas pela sociedade (Semerene, 1999), mas também produzir abertura para outras performances, simulações e significados, muitas vezes produzidos no anonimato (Brown, Maycock, Burns, 2005; Ross, 2005). É o caso, por exemplo, da construção de redes afetivas e sociais entre gays, lésbicas, bissexuais, travestis, transexuais e outras identidades, em uma perspectiva mais descentrada, flexível e múltipla (Turkle, 1999).

Foi a partir, então, de uma discussão sobre as novas possibilidades da internet, de troca de experiências e encontros eróticos, que desenvolvi uma pesquisa de base etnográfica (2004-2007) sobre a relação entre risco e prazer no momento atual da epidemia de HIV/Aids, no contexto brasileiro²; mais precisamente, sobre a prática do barebacking, geralmente definido como o sexo anal desprotegido entre homens de forma intencional (Elford, 2006; Shernoff, 2006; Halkitis, Parsons, Wilton, 2003; Suarez, Miller, 2001), ainda que haja diferenças quanto ao tipo de vínculo e condição sorológica dos parceiros envolvidos. Nesse sentido, alguns autores buscam delimitar melhor o conceito (e o grupo de praticantes), considerando, por exemplo, se o sexo anal intencional ocorre entre homens que 'não são parceiros primários' (Mansergh et al., 2002), ou, mais especificamente, definindo o barebacking como o sexo anal sem preservativo de forma intencional, 'exceto quando praticado por parceiros primários HIV negativo' que mantêm um relacionamento mutuamente monogâmico ou em um relacionamento de proteção negociada (Wolitski, 2005) ${ }^{3}$.

O conceito, entretanto, tem sido 'usado' pelos atores que praticam o sexo desprotegido de forma diversa. É o caso, por exemplo, quando homens que se relacionam afetivo-sexualmente com outros homens passam a caracterizar o barebacking como qualquer sexo anal desprotegido, independentemente do tipo de parceria (se fixo ou ocasional) ou, mesmo, da intencionalidade do ato (Silva, 2008; Huebner, Proescholdbell, Nemeroff, 2006; Shernoff, 2005).

\author{
${ }^{2}$ Trata-se mais \\ especificamente de \\ uma tese de doutorado, \\ defendida em abril de \\ 2008, no Instituto de \\ Saúde Coletiva (UFBA) \\ sob a orientação do \\ Prof. Dr. Jorge Iriart. \\ Parte deste trabalho \\ foi desenvolvida \\ durante meu estágio de \\ doutorando no exterior \\ na UQAM (Canadá), \\ financiado pela Capes, \\ sob a orientação do \\ Prof. Dr. Joseph Lévy. O \\ projeto de pesquisa foi \\ aprovado pelo Comitê \\ de Ética do Instituto \\ de Saúde Coletiva da \\ Universidade Federal da \\ Bahia.
}

${ }^{3}$ Este autor busca incluir diferentes tipos de sexo anal desprotegido de forma intencional por exemplo, entre parceiros primários sorodiscordantes ou entre parceiros primários soroconcordantes HIV positivo, na medida em que as relações possam apresentar risco de infecção/reinfecção para algum deles. 
Neste artigo, desenvolvo algumas dessas discussões produzidas no decorrer de uma trajetória de pesquisa online sobre o barebacking no Brasil, pensando também as possibilidades abertas pelas novas tecnologias de informação para as interações afetivo-sexuais masculinas. Dessa forma, torna-se importante discutir ou compreender a cibersexualidade como um espaço de disseminação de novos discursos e modelos sexuais (Lévy, Garnier, Thoer-Fabre, 2006) - por exemplo, sobre a intensificação do prazer sensorial, maior contato e intimidade entre os parceiros no sexo sem camisinha (Silva, 2009; Huebner, Proescholdbell, Nemeroff, 2006; Halkitis, Parsons, Wilton, 2003; Mansergh et al., 2002) apesar, também, de reproduzir valores morais.

Este artigo, portanto, busca focalizar essas novas facetas da internet, incluindo a potencialidade das pesquisas online para a compreensão de aspectos do homoerotismo masculino. Mais especificamente, busca problematizar algumas tensões e ambiguidades conceituais do barebacking, sobretudo no que diz respeito à relação entre sexo desprotegido entre parceiros fixos e sexo (desprotegido) ocasional ou 'promíscuo', de acordo com a discussão desenvolvida por alguns usuários da internet no contexto brasileiro.

\section{Considerações sobre a trajetória de pesquisa na internet}

Em 2006, após uma pesquisa de reconhecimento do 'campo', na internet, utilizando suas ferramentas de busca, encontrei algumas comunidades do orkut que discutiam as práticas do barebacking, bem como os aspectos positivos em relação ao não uso da camisinha. Durante essa trajetória, como forma de acompanhar os grupos de discussão, foi criado um e-mail e uma página específica no orkut, com informações importantes da pesquisa. Após aproximadamente um ano e cinco meses de observação participante online (abril de 2006 a setembro de 2007), pude participar de alguns fóruns criados diretamente para a discussão sobre o barebacking ou sobre o sexo sem camisinha.

A maioria das comunidades do orkut girava apenas em torno do sexo sem camisinha ou da preferência por 'gozar dentro', muitas vezes destacando os aspectos negativos do uso do preservativo. Na maioria delas, portanto, não havia nenhuma referência direta, na sua descrição, ao barebacking. Para minha surpresa, cheguei a encontrar no orkut algo em torno de quarenta comunidades mais genéricas que valorizavam positivamente o sexo sem camisinha. Em contrapartida, foram identificadas sete comunidades diretamente vinculadas ao tema do barebacking, uma delas posicionando-se contra o mesmo.

Por sua vez, para viabilizar a coleta de dados, busquei acompanhar a lógica do próprio orkut: no espaço organizado para a descrição do meu perfil, descrevi toda uma postura ética que orientaria a pesquisa. A descrição sobre a condução do trabalho, objeto e objetivos também foram ressaltados. Na mesma página, foram inseridos meus dados profissionais e vínculos institucionais. No decorrer do trabalho, cada novo tópico para um fórum ou mensagem criada por mim em uma comunidade, às vezes apenas informando e convidando seus membros para a participação em uma pesquisa de doutorado sobre o barebacking, possibilitou que qualquer participante entrasse na minha página pessoal e conhecesse melhor as condições do trabalho de tese.

Neste processo de 'participação ativa', buscava criar um 'espaço' de diálogo com outros membros das comunidades, inclusive relatando minhas próprias dúvidas sobre a prática do barebacking, como também dar visibilidade à minha pesquisa a partir dos fóruns de discussão. Por outro lado, buscava 'conhecer' as nuances interativas da 'rede' e 'estranhar' o que aparentemente me era 'familiar'. Como já enfatizado por Da Mata (1978, p.28), os estudos etnográficos envolvem uma tarefa dupla: "transformar o exótico no familiar e/ou transformar o familiar em exótico".

No que concerne à dinâmica de participação e contato nas comunidades do orkut, alguns aspectos devem ser esclarecidos. No momento em que cada membro do orkut cria ou participa de alguma comunidade, todas elas ficam visíveis na respectiva página do usuário, no meu caso na página de Augusto Silva. Por sua vez, todos os membros de cada comunidade também ficam registrados e visíveis na página da comunidade. É muito fácil estabelecer contato, na forma de 'amigos', ou simplesmente enviar mensagens (scraps - recados) e depoimentos para cada participante. Quando um membro de uma comunidade participa de um fórum de discussão, ele pode ficar anônimo ou ser 
identificado imediatamente. Para mim, ser identificado foi uma forma interessante de outro membro entrar em contato comigo ou visitar a minha página e perfil, conhecendo melhor aspectos da pesquisa. Vale ressaltar que é comum encontrar no orkut membros que participam de várias comunidades simultaneamente, a partir de seus interesses em foco, como é o caso do barebacking.

Periodicamente, também passei a receber convites de alguns membros para participar de sua rede de amigos (no orkut, há uma seção correspondente da página em que os amigos ficam identificados, possibilitando que se estabeleçam redes de amizade ou contato). Nos fóruns, as mensagens, dispostas em uma sequência ordenada por data e hora de envio, também podem tomar a forma de um diálogo, quando os membros respondem uns aos outros. Frequentemente, as respostas acabam se direcionando para o tópico-guia do fórum em questão, ou mesmo para alguns dos participantes que enviam uma mensagem polêmica, por exemplo, criticando ou censurando a prática do barebacking.

A estratégia de acompanhar grupos e fóruns de discussão na internet possibilitou o acesso a praticantes do barebacking ${ }^{4}$, já que isso seria mais difícil de ocorrer de forma offline, sobretudo porque a internet vem servindo como fonte de conhecimento e difusão da prática (Grov, 2006; Halkitis, Parsons, 2003; Halkitis, Parsons, Wilton, 2003; Tewksbury, 2003; Gauthier, Forsyth, 1999). Deve-se, também, considerar que as interações online privilegiam o anonimato das pessoas, facilitando a abordagem e acesso a temas polêmicos. Outro aspecto importante é que pude ter uma ideia geral da prática, considerando os distintos lugares e espaços de ocorrência no contexto brasileiro, a partir de um computador. Vale lembrar também que o orkut, filiado ao Google, tem se destacado no cenário brasileiro ${ }^{5}$ como uma rede social importante, permitindo pôr em relação os amigos de amigos, ou simplesmente criar novas amizades e manter relacionamentos; propiciando a circulação e discussão de temas diversos.

Com a criação da minha página no orkut, foi possível, também, solicitar a participação de voluntários para uma entrevista online, utilizando o recurso do MSN Messenger existente para a conversa em tempo real. Qualquer interessado na pesquisa pôde ter acesso ao meu endereço eletrônico para contato, visível na página do orkut. Cada novo convite de um usuário para 'entrar' (ser incluído) no meu MSN significava uma resposta positiva para participar da pesquisa, ainda que esses interlocutores pudessem desistir ou retirar seu consentimento a qualquer momento ${ }^{6}$.

Finalmente, deve-se destacar que foram mantidos os estilos e usos de linguagem das mensagens dos fóruns reproduzidas no decorrer deste artigo. É possível que alguns dos recursos ou signos utilizados para complementar ou construir enunciados, como imagens e símbolos disponíveis na internet, tenham se perdido no momento de transferi-los e salvá-los como documento do Word; ou mesmo quando foram trabalhados no QSR Nvivo (software específico usado para o tratamento e armazenamento de dados qualitativos).

\section{Barebacking não é promiscuidade: novas discussões em rede}

No que diz respeito às descrições e explicações sobre o conceito de barebacking entre usuários brasileiros, é preciso chamar atenção para dois aspectos importantes que se apresentam de forma antagônica ou conflituosa: o sexo desprotegido com um parceiro fixo ou com uma pessoa de confiança e o sexo casual com desconhecidos ${ }^{7}$. Nesta perspectiva, o barebacking pode ser entendido como qualquer prática sexual sem camisinha, mesmo com alguém de confiança, ou apenas quando o sexo desprotegido ocorre fora de um contexto de

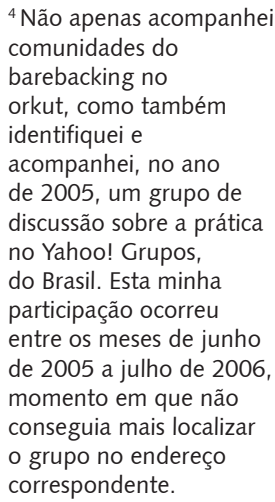

${ }^{5}$ Lançado em 2004 o orkut atualmente é muito difundido entre os usuários brasileiros. De acordo com Morais e Rocha (2005), em 2005 , já havia $71,8 \%$ de brasileiros em uma comunidade de 6,2 milhões de pessoas.

${ }^{6}$ Os textos produzidos no MSN Messenger não serão tratados neste artigo, mas apenas algumas mensagens produzidas em fóruns de discussão do orkut. Alguns dos relatos produzidos no MSN Messenger, referentes aos sentidos e práticas do barebacking no Brasil, podem ser encontrados em Silva (2009).

\footnotetext{
${ }^{7}$ A discussão sobre estes aspectos é importante porque evidencia alguns dos 'deslizamentos' atuais ou distintas maneiras de se compreender o conceito de barebacking. É o caso, por exemplo, quando alguns dos usuários da internet não reconhecem o tipo de vínculo entre os parceiros como necessário para a definição do barebacking; isto é, que o sexo anal desprotegido (de forma intencional) deve ocorrer entre parceiros que 'não são estáveis ou primários'.
} 
comprometimento mútuo. Assim, é possível problematizar ou definir o barebacker a partir de uma imagem da 'promiscuidade' ou do 'gay promíscuo', tanto quanto defender que o barebacking pode ocorrer em uma relação estável ou duradoura, em que existe fidelidade e confiança, em oposição à imagem difundida do sexo promíscuo sem camisinha ou da prática promíscua de bareback:

"Acho q não usar camisinha não faz do cara barebacker. Se os dois são casados e são comprometidos e fieis, eles não são barebackers. Barebackers implica em sexo promiscuo sem camisinha". (Participante do fórum $\mathrm{O}$ que rola no bareback1?).

"A linha que separa a prática de bareback da promiscuidade é bem mais larga que a espessura de um preservativo. Não defendo a prática promíscua de bareback. Existem pessoas que são como cães no cio soltos na rua, essas sim correm um seríssimo risco de contrair seja que doença for através do bareback. Porém se existe uma relação duradoura de confiança e fundamentada em testes pelo menos de 2 em 2 meses, acredito que até certo ponto a prática do bareback pode ser saudável". (Participante1 do fórum Bareback Não é Promiscuidade).

\footnotetext{
“Bareback é só putaria? Estou num relacionamento há sete anos e nunca usamos preservativo. Que eu saiba, bareback é o nome dado ao sexo sem camisinha, não importando se ocorra numa relação estável ou casual, se é com uma ou com várias pessoas. Relacionar a prática do bareback à promiscuidade é uma linha de pensamento estranha. Cabe lembrar que o uso da camisinha só ficou difundido a partir dos anos 90, após muito sugestionamento das campanhas veiculadas na mídia e na ação de grupos de combate à AIDS. Mais estranho ainda é taxarem quem prefere fazer sexo sem preservativo a pessoas soropositivas. São mais estigmas criados no nosso meio, rótulos que só servem para o meio gay mais sectário". (Participante2 do fórum Bareback Não é Promiscuidade).
}

Em se tratando do tipo de vínculo relacional entre as pessoas envolvidas na prática sexual desprotegida, existe um elemento central que tanto pode diferenciar o barebacking de qualquer outro sexo sem camisinha quanto estabelecer uma linha distintiva e valorativa em torno de algumas modalidades de práticas de barebacking, que é a imagem disponível da promiscuidade. Nessa trajetória discursiva sobre as práticas sexuais, a referência ao gay promíscuo parece ser frequentemente utilizada para lembrar a hierarquia de valores sexuais, separando o que seria um bom ou mau sexo (Rubin, 1984). Portanto, mesmo no interior das práticas homoeróticas, a imagem da promiscuidade serve para distinguir estilos de vida e identidades gays, por exemplo, entre aqueles que seriam promíscuos e os que se aproximariam de uma relação mais saudável, equilibrada, normal, racionalizada, passível de ser autorregulada. É interessante lembrar que a palavra promiscuidade significa, na língua portuguesa, qualidade

${ }^{8}$ Definição retirada do dicionário Aurélio da língua portuguesa. A palavra promíscuo, por sua vez, significa misturado, confuso, indistinto. de promíscuo, mistura desordenada e confusa ${ }^{8}$. Ser promíscuo, portanto, pode significar, em última instância, alguém que confunde ou transgride a ordem das coisas, por exemplo, quando passamos a agir orientados, primordialmente, por nossos impulsos, desejos e paixões e nos misturamos com os outros, 'perdendo' a dimensão racional de quem somos. 
Com base no discurso da promiscuidade, o barebacker não seria apenas aquele que pratica sexo sem camisinha, já que potencialmente pode ser qualquer um de nós, mas aquele que se aventura sexualmente com desconhecidos. Em contrapartida, aparece ainda, nos enunciados online, um tipo de barebacking que pode ser saudável em detrimento daquele que potencializa o surgimento de doenças. O promíscuo, aquele que participa de orgias, surubas, da putaria, que arrasta qualquer um em qualquer momento pra transar, que é como cão no cio solto na rua, que sai com um cara na balada sem saber nem mesmo quem é essa pessoa, serve como protótipo ou modelo discursivo para legitimar uma modalidade mais segura e menos selvagem de barebacking:

\begin{abstract}
"Bareback, no sentido inicial é transar sem camisinha. Como faziam no passado não tão remoto. Porém, a vulgarização das pessoas gerou um desvio de prática que se vê as vezes as pessoas falando, que é "orgia sem camisinha". Esses que transam com qualquer pessoa, que no linguajar gay "arrastam" qualquer um em qualquer momento pra transar, e os outros que fazem orgias (pense no risco) sem camisinha é que terminam por detonar a coisa". (Participante1 do fórum Bareback Não é Promiscuidade)
\end{abstract}

“[...] Transar sem camisinha é bareback. Com qualquer pessoa, até o mendigo da rua, também é bareback. Porém BAREBACK NÃO É PROMISCUIDADE. É PRÁTICA SEXUAL SEM CAMISINHA. Entendase que promiscuidade é sair e transar com um cara na balada sem saber nem mesmo quem é essa pessoa. Nesse caso não precisa haver penetração para se contrair uma doença infecto contagiosa. Não vem ao caso citar pessoas que se infectaram com HIV ou seja com o que for. Se fizessem testes para doenças infecto contagiosas pelo menos de 2 em dois meses como eu faço junto com meu namorado estariam mais seguros. Ou pelo menos estariam constantemente lembrando-se do seu compromisso de fidelidade e de sexo seguro se resolvessem transar com outra pessoa [...]". (Participante1 do fórum Bareback Não é Promiscuidade)

A preocupação excessiva por demarcar uma condição saudável de barebacking, quando o sexo desprotegido não representa, necessariamente, um problema (ou perigo) para as pessoas (por exemplo, com o namorado, mediante a realização de testes para doenças infectocontagiosas) ${ }^{9}$, talvez mostre o modo (e intensidade) como o discurso sobre o 'sexo seguro sempre' passou a estar vinculado a uma norma geral de 'boa conduta' para o funcionamento saudável dos corpos e relacionamentos. Consequentemente, o outro (homossexual) que pratica o sexo desprotegido tornou-se indesejável - abjeto ${ }^{10}$. Esta "incongruência" de sentido utilizada para falar sobre o barebacking está presente nas mensagens de um participante do fórum Bareback Não é Promiscuidade, que tenta esclarecer e pôr em seu devido lugar o conceito de barebacking, especialmente no que se refere à distinção entre sexo sem camisinha em uma relação estável, como sendo sexo seguro, e o bareback, como o prazer de transar com o maior número de pessoas sem pegar qualquer doença, ou simplesmente como sendo o sexo casual com estranho sem camisinha:

"Na verdade existe muita diferença entre o sexo sem camisinha e o bareback. Esta ultima, literalmente, e um termo que sempre existiu

\author{
${ }^{9}$ Sugere-se aqui que \\ o barebacking ocorre \\ também entre 'parceiros \\ primários HIV negativo'. \\ ${ }^{10}$ Nas palavras de \\ Butler (2003, p.191), "o \\ 'abjeto' designa aquilo \\ que foi expelido do \\ corpo, descartado como \\ excremento, tornado \\ literalmente "Outro'".
}


no inglês pra definir a prática da montaria em cavalos sem qualquer proteção (dorso nu, ao pé da letra) e que passou a ser utilizada após o advento da AIDS, principalmente nos EUA, pelos adeptos do sexo sem proteção e no final das contas muitos deles admitiam que era sexo promíscuo, apesar de não se definirem como promíscuos. Para alguns destes o real prazer desta prática era o prazer de transar com o maior número de pessoas sem pegar qualquer doença, tanto que chegavam a fazer disputas de quem transava mais sem se contaminar. Há alguns anos estive em NYC e recebi um convite de uma "bareback party" no qual os promotores deixavam claro que haveria um número " $\mathrm{x}$ " de doentes, claro que esse tipo de festa faz parte de um submundo, mas este era o prazer deles. Tanto é que o que muitos acima definiram como bareback, eles lá chamam de "safe sex", ou seja pra eles o sexo seguro significa transar com camisinha nas relações casuais (mesmo que seja uma suruba) e transar sem camisinha numa relação estável, muito diferente de bareback.

Sei que muitos não irão concordar com o exposto, não inventei nada, basta pesquisar na net que vão encontrar... no entanto, como sempre, todos vão preferir continuar usando o termo bareback por acharem mais "culto" ... chique, até...

Abraços". (Participante3 do fórum Bareback Não é Promiscuidade)

\begin{abstract}
"No real sentido do barebacker ele nao ta fazendo isso pra adoecer mas sabe $q$ isso pode acontecer e nao tem medo, ao contrário sente até mais prazer nisso, claro q exagerei colocando o exemplo das festas $q$ vi acontecer nos eua mas isso tb existe no fato de se fazer sexo casual sem camisinha. O q nao combina com bareback é o q muita gente fala: "ah, so faco bareback com meu namorado". Isso nao existe, isso eh sexo seguro, eh o q a maioria das pessoas fazem. Mas se for sexo casual com estranho ai sim esta caracterizado o bareback". (Participante3 do fórum Bareback Não é Promiscuidade).
\end{abstract}

${ }^{11}$ Neste contexto, as práticas do barebacking aparecem associadas a uma estratégia de resistência ao discurso normativo da saúde em relação ao sexo seguro (Crossley, 2002; Rofes, 2002). É interessante destacar que o termo barebacking, como sexo anal sem preservativo, aparece também associado a alguns nomes de atores pornôs gays, soropositivos, que, em meados de 1990, passam a declarar publicamente sua intenção de não usar mais a camisinha no sexo anal. Este foi o caso de Scott O'Hara, que aparece também como o primeiro, em 1995, a criar a expressão barebacking para descrever o sexo anal desprotegido

(Huebner, Proescholdbell, Nemeroff, 2006).
Se o barebacking é sexo promíscuo sem proteção ou sexo casual com estranho, há de se problematizar diferentes aspectos e elementos que estão presentes no cotidiano dos encontros afetivo-sexuais que ocorrem casualmente. Nesta perspectiva, entra em questão a própria concepção de intencionalidade como necessária para delimitar a prática do barebacking, ou seja, o engajamento consciente e deliberado em práticas de sexo anal desprotegido, conhecendo-se os riscos envolvidos (Suarez, Miller, 2001).

No entanto, a partir da perspectiva dos que se consideram praticantes do barebacking, a intencionalidade (desafio) do risco nem sempre estará presente de forma clara ou decisiva; ou seja, o conceito de barebacking pode implicar apenas sexo sem camisinha, independentemente da intenção do ato. Para exemplificar esta problemática, vale destacar a opinião de alguns dos participantes de diferentes fóruns de discussão, inclusive sem diferenciar a prática do barebacking pela identidade sexual (homossexual), aproximando ou colocando heterossexuais e homossexuais na mesma categoria, fazendo referência fundamentalmente ao sexo desprotegido. Este aspecto da identidade sexual é interessante, porque coloca em xeque a ideia de que o barebacking ocorre apenas entre 'homossexuais'. Evidentemente, não podemos esquecer que o barebacking surge de dentro da 'comunidade gay', em meados de 1990, para designar o sexo desprotegido (Léobon, Frigault L-R, 2005) ${ }^{11}$. Em contrapartida, também não podemos 
negligenciar outros 'deslizamentos' de sentido, quando o conceito de barebacking é 'usado' de forma genérica, sem referência ao sexo anal desprotegido entre homens (homossexuais) ou mesmo à 'intencionalidade' do ato:

“1) Bareback é transar sem camisinha.

Mas tem muito hétero que transa e num tá nem aí.

Olha a quantidade de mulheres solteiras que ganham neném.

Tudo transando sem camisinha e jogam a culpa da promiscuidade em cima dos viados.

Hipocrisia". (Participante do fórum ' Vc é bareback?')

“2) Fazer sexo sem camisinha é praticar bareback.. você pode não sentir prazer mas fazer com camisinha.. mas se você pratica sem é um "barebacker".. quando se confia e gosta não vejo nenhum problema". (Participante1 do fórum $\mathrm{O}$ que rola no bareback?)

\section{“3) É LEITE DENTRO MESMO.}

bareback é (montar sem arreios) ou seja quando vc monta numa pica sem camisinha é o mesmo q montar num cavalo sem arreios ou seja: sem proteção alguma, daí a palavra BAREBACK". (Participante2 do fórum O QUE ROLA NO BAREBACK?) ${ }^{12}$

Diante do que foi exemplificado, existe um tópico central que mobiliza o discurso sobre o barebacking, que é a ausência ou abandono da camisinha. Um dos membros (número 1) posiciona-se de forma direta quando diz que bareback é transar sem camisinha, independentemente da identidade sexual, o que o faz criticar muitos heterossexuais com sua hipocrisia ao jogar a culpa da promiscuidade em cima dos viados, ainda que não se posicione explicitamente como gay ou homossexual. Neste discurso, a prática comum do sexo sem camisinha entre heterossexuais e a pouca importância ou preocupação com o uso da mesma parecem mover-se para o centro do discurso, como uma forma de deslocar o foco de análise dos homossexuais, deixando dúvida se o tipo de vínculo entre os parceiros faria alguma diferença conceitual para o sexo desprotegido.

Na segunda descrição (número 2), o barebacking é definido como fazer sexo sem camisinha, e o barebacker, como uma pessoa que pratica sexo sem (camisinha). Por outro lado, este membro parece reconhecer que existe uma 'escolha' ou 'opção' pelo prazer da prática sexual sem camisinha, na medida em que uma pessoa pode não sentir prazer com a camisinha, mas continuar a usá-la. No que diz respeito ao vínculo afetivo implicado no sexo desprotegido, este membro também sugere que o tipo de parceria não seria um elemento diferenciador do barebacking, mas também procura focalizar o contexto de confiança e afeto da prática em uma dimensão 'não problemática'. Nessa perspectiva, ele fala de confiar e gostar ${ }^{13}$. O fato de o membro sugerir alguma concessão para o ato (quando se confia e gosta) parece implicar uma valorização em torno dos vínculos afetivos entre as pessoas, já que seria pouco provável não gostar da prática sexual sem camisinha e fazê-lo, diferentemente do sexo desprotegido com parceiros casuais ou desconhecidos que pode ocorrer mesmo sem vínculo afetivo com o parceiro.

Finalmente, apenas uma das descrições acima (número 3) assinala, de forma enfática, ${ }^{14}$ o contato direto com o esperma do homem (leite ou porra), o que nos possibilita pensar sobre a condição de gozar dentro no sexo sem camisinha,

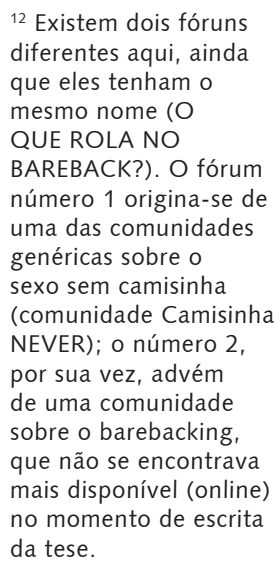

${ }^{13} \mathrm{O}$ verbo gostar possibilita pensar em dois 'objetos' ou direções da ação (uma pessoa e a própria prática desprotegida). Preferi, entretanto, colocar os verbos confiar e gostar mais próximos ou complementares entre si, ou seja, em direção à pessoa envolvida na relação sexual, tentando acompanhar um sentido específico do enunciado em comparação aos discursos mais gerais sobre o prazer do sexo sem camisinha.

\footnotetext{
${ }^{14}$ Este participante utiliza alguns recursos linguísticos e estilísticos para destacar uma ideia, por exemplo, com o uso da palavra mesmo, designando verdadeiramente, realmente, e toda a frase escrita em maiúscula.
} 
${ }^{15}$ A retirada do pênis antes da ejaculação é uma das estratégias de 'redução de danos' utilizadas por alguns homens que se autodenominam praticantes de barebacking (barebackers). Destaca-se também a 'preferência' por ser ativo ou passivo (posicionamento estratégico) e a busca por manter relações sexuais desprotegidas com homens do mesmo status sorológico (serosorting) (Grov, 2006; Shernoff, 2006; Parsons et al., 2005; Suarez, Miller, 2001).

16 É importante esclarecer que o barebacking também não se encontra, necessariamente, vinculado à intenção ou busca por contrair o HIV. Este é o caso dos bug chasers (caçadores de vírus), quando um homem HIV negativo procura deliberadamente um homem HIV positivo para ser infectado (Gauthier, Forsyth, 1999). Deve-se, então, ressaltar que muitos barebackers (negativos e positivos) aparecem como indiferentes ou ambivalentes em relação ao status sorológico de seus possíveis parceiros

(Grov, Parsons, 2006; Tewksbury, 2003). sem nenhuma proteção ou cuidado, como elemento definidor da prática do barebacking. No entanto, ainda que este aspecto seja uma marca importante em outros discursos, existem homens que preferem o barebacking sem gozar dentro $^{15}$ (Silva, 2008).

Quando se fala, então, que o barebacking é sexo casual com estranho, parece que todos que praticam ou praticaram sexo casual com um estranho, em algum momento da vida, sem proteção, estariam praticando o barebacking, independentemente se houve algum relapso (esquecimento, omissão, concessão) ou intenção de não usar a camisinha. Na mesma direção, é possível também problematizar alguns deslocamentos de sentido para os conceitos de promíscuo (sexo promíscuo sem proteção) e estranho. Nas interações cotidianas, nem sempre será fácil estabelecer um critério preciso (objetivo) que organize estes conceitos. Por exemplo, o sexo sem grandes compromissos afetivos, independentemente do número de parceiros, com pessoas tidas como conhecidas ou confiáveis (vizinhos, colegas, amigos ou amigos dos amigos etc.) talvez não signifique, para muita gente, sexo promíscuo. Em contrapartida, existe uma variabilidade de situações e elementos que justificam ou mobilizam a prática sexual (des)protegida, inclusive com desconhecidos, sem as pessoas se sentirem, necessariamente, promíscuas. O mesmo ocorre com os critérios utilizados para distribuir as pessoas em níveis de familiaridade ou confiabilidade. Nem sempre o tempo de relacionamento ou contato (podendo ser descrito em horas, dias, meses, anos etc.) será tido como um bom descritor para definir quem é ou não um estranho. O que estou querendo dizer é que os aspectos ou linhas fronteiriças que aproximam (ou separam) o barebacking do sexo promíscuo sem proteção ou casual com estranho nem sempre estarão bem organizados ou claramente definidos no cotidiano afetivo-sexual das pessoas, podendo ser alterados ou reorganizados a partir dos interesses e aspectos morais em jogo. Não é à toa, por exemplo, que a ideia da promiscuidade sempre esteve mais vinculada às práticas homoeróticas masculinas.

Por fim, vale ressaltar que distintos encontros sexuais desprotegidos, com parceiros desconhecidos, ocorrem não apenas em contextos específicos, como as festas previamente organizadas, em que os participantes sabem da existência (possível) de pessoas com HIV, mas em outras situações diversas do cotidiano, em que o tesão do momento (e 'dos parceiros') pode fazer com que o uso da camisinha seja algo dispensável, secundário ou menos importante ${ }^{16}$. Nessa perspectiva, a relação entre risco e prazer também está presente em vários outros contextos de interação sexual, para além do "bareback party", quando as pessoas têm consciência (e medo) de que podem adoecer ou correr qualquer outro perigo, mas parecem apostar no prazer intenso que sentem nestas situações tidas como arriscadas ou perigosas:

"[...] então repito, claro que tem barebackers que exageram realmente e não estão nem aí para as doencas, até se divertem com elas, mas tem aqueles que curtem o bareback mas com muito medo de doenca, o q não deixa de ser comportamento de risco como citou alguém em algum comentário [...]". (Participante3 do fórum Bareback Não é Promiscuidade).

"Aconteceu

Eu fui no (estabelecimento $X$ ). Tinha um cara lá que eu chamo de excesso de homem. Grandão, cabeludo e cacetudo. Ô dilícia. Toda hora eu dava uma encostada nele. Fui para aquela parte mais escura, onde 
tem uma grade, e ele foi atrás de mim. Fiquei atrás da grade olhando o movimento e ele chegou por trás roçando. Tirou aquele pintão melado e começou a passar na minha bundinha lisinha. Ai que frio na espinha, sinto só de lembrar.

O pau estava melado e rapidinho ele conseguiu penetrar. Até lembrei da camisinha, mas àquela altura nem dava pra pegar. Ele mandou eu abaixar e segurou na grade enquanto metia. Foi bom demais. Fudia muito forte e rapidinho já tinha uma roda de caras se masturbando e olhando.

Comecei a pegar, masturbar e chupar vários que estavam perto até que um gozou na minha boca. Eu precisava lavar e acho que por isso aquele excesso de homem não gozou no meu rabo.

Ainda bem. Se tivesse acontecido eu ia ficar muito preocupado, mas foi bom demais. Ai como eu adoro uma putaria, hihihi." (Participante do fórum Conte a Sua Experiência)

Conforme enfatiza Lupton (1999), o prazer no risco está intimamente vinculado à ideia de transgressão (ou violação) de fronteiras e oposições (dentrofora, eu-outro, natureza-cultura etc.). Podemos, então, seguir uma perspectiva analítica que concebe as práticas eróticas intimamente ligadas ao risco ou perigo, sobretudo quando o erotismo é visto como uma maneira de colocar em xeque a ordem e regularidade da vida ou a descontinuidade dos seres (Bataille, 2004). Entretanto, a possibilidade de transgredir 'limites' estabelecidos socialmente, incluindo os que separam e distinguem corpos e identidades, mobiliza também diferentes (e ambíguos) sentimentos e emoções, entre eles, medo, ansiedade, preocupação e culpa.

\section{Considerações finais}

Conforme trabalhado neste artigo, o conceito de barebacking não circula de forma fixa e imutável, sendo apropriado (e transformado) diferentemente pelos usuários. É importante considerar, aqui, os efeitos e usos (práticos) da linguagem, podendo produzir múltiplos sentidos (Spink, Medrado, 1999; Potter, 1997) ${ }^{17}$. Não estou dizendo com isso que o termo 'barebacking' não tenha mais nenhuma utilidade, inclusive porque ainda produz um efeito sobre seus "ouvintes" e "locutores", especialmente quando oferece indícios de que alguém 'prefere' ou pratica sexo sem borracha. O que quero ressaltar, portanto, é que os atores que se dizem praticantes não são, necessariamente, mais os mesmos, tampouco entendem o conceito da mesma forma, o que exige uma reflexão mais ampla sobre seus distintos usuários e contextos de uso.

Essa transformação de sentidos abre a perspectiva de novos estudos (online e offline) para acompanhar a circulação e usos dos termos barebacking e barebacker em contextos e tempos diversos. Esses estudos, por sua vez, devem buscar compreender a forma como os (novos) discursos sobre o sexo sem camisinha passam a ser utilizados entre pessoas diversas, com múltiplos posicionamentos identitários ${ }^{18}$. É importante lembrar que as identidades são sempre múltiplas, fluidas, com uma variedade de maneiras de combinação e interseções, através das modalidades de gênero, raça, sexo, idade, classe social etc. (Butler, 2003). Como sinalizado neste artigo, 'a identidade' do barebacker também não se apresenta de forma única, homogênea, estável ou fixa. Há conflitos, tensões, disputas, poder, valores e posicionamentos em jogo. Essas

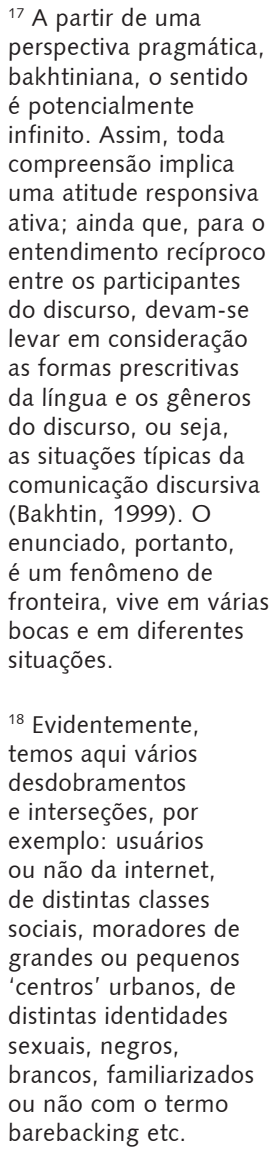

${ }^{18}$ Evidentemente, temos aqui vários desdobramentos e interseções, por exemplo: usuários ou não da internet, de distintas classes sociais, moradores de grandes ou pequenos 'centros' urbanos, de distintas identidades sexuais, negros, brancos, familiarizados ou não com o termo barebacking etc. 
${ }^{19}$ Refiro-me aqui à discussão sobre o crescimento do risco de infecção por HIV e outras doenças sexualmente transmissíveis entre homens que fazem sexo com homens a partir do uso da internet (Elford, 2006; Benotsch, Kalichman, Cage, 2002; Bull, Mcfarlane, Rietmeijer, 2001).

${ }^{20}$ Deve-se destacar que a internet é utilizada também como uma 'forma' de proteção, na medida em que ocorre o estabelecimento de papéis' e 'expectativas' anteriores ao encontro 'face a face' (Brown, Maycock, Burns, 2005). identidades ('gays' que praticam o 'barebacking') são, portanto, fluidas, instáveis e políticas (Yep, Lovaas, Pagonis, 2002).

Entretanto, mesmo com essas instabilidades conceituais, torna-se importante reconhecer a existência do barebacking, com suas fronteiras e tensões (barebacking/sexo sem camisinha); discuti-lo(s) abertamente e coletivamente (dentro e fora da internet); tirá-lo(s) da 'marginalidade'; considerá-lo(s) como uma dimensão possível e legítima das experiências eróticas e afetivas; bem como compreender (e discutir) os distintos interesses e sensações envolvidos no sexo desprotegido, as estratégias utilizadas no cotidiano de atores diversos para não se usar o preservativo (como formas de redução ou minimização dos riscos) e os múltiplos significados produzidos em torno das práticas sexuais desprotegidas.

Seria, então, uma visão estreita, simplista e mesmo incongruente pensar a internet apenas como propiciadora da epidemia de HIV/Aids, ou fixá-la como contexto de práticas de risco ${ }^{19}$. Entretanto, a internet pode favorecer a prevenção, por exemplo, ao produzir informação e discussão sobre estratégias de redução de danos para a realização do barebacking (Grov, 2006) ${ }^{20}$. Em se tratando das relações entre internet, cultura e risco, talvez seja mais pertinente discutir a reciprocidade e os múltiplos efeitos destas interações. Miller e Slater (2004), por exemplo, enfatizam o relacionamento complexo e imbricado entre mundos online e offline. São vários usos e interesses envolvidos entre os distintos atores, podendo ocorrer mútuas (e múltiplas) transformações: da tecnologia, dos próprios usuários e de suas culturas. Nesse sentido, deve-se, também, ressaltar que o 'sexo bareback' não ocorre apenas a partir da internet, na medida em que há uma 'diversidade' de espaços e abordagens para os encontros e realização do mesmo (Silva, 2008; Halkitis, Parsons, Wilton, 2003; Mansergh et al., 2002).

Finalmente, no que concerne às 'emoções' presentes nos discursos sobre o sexo desprotegido/barebacking, gostaria de destacar alguns aspectos. O autor construcionista Kenneth Gergen (1999) entende as emoções constituídas de forma dialógica e performativa. Este autor fala de cenários emotivos (Gergen, 1999), na medida em que as emoções, como performances, também adquirem sentido em cenários relacionais específicos. Nessa direção, as emoções seriam também públicas como qualquer ação social.

Reconheço a importância do construcionismo ao destacar que as emoções são nomeadas e compreendidas no interior de práticas discursivas, e que as nossas posições relacionais podem mobilizar múltiplos sentidos. Entretanto, concordo com Lupton (1998) quando diz que não se deve negligenciar uma dimensão sensual, material, corporal das experiências emotivas. Como a autora assinala, a corporeidade está inextricavelmente integrada à subjetividade (Lupton, 1998).

Dessa forma, torna-se importante reconhecer que o modo como as pessoas respondem às 'regras' e 'estruturas' sociais também é mediado pelas experiências sensuais ou sensoriais vividas no corpo (Shilling, Mellor, 1996). Para além de um discurso que enfatiza a 'intenção' (reflexiva, consciente ou racional) de não usar a camisinha, é importante considerar que muitas decisões são tomadas à 'flor da pele', ou seja, no calor das interações sexuais, quando as pessoas parecem perder o 'autocontrole'; ou mesmo levando em consideração 'sentimentos' de intimidade e confiança no parceiro.

Portanto, as 'posições relacionais' também são (de)marcadas a partir da 'materialidade' do corpo, aberto e passível de ser transformado pela mediação de objetos, artefatos culturais e de outros corpos. Esta diferença sugere uma leitura mais crítica (e criativa) das abordagens disponíveis, entre elas o próprio construcionismo, no sentido de imaginar novos modelos teóricos que considerem a materialidade (experiência vivida) de um corpo que é, 'simultaneamente', 
cultural, social, histórico e político; portanto, sem reduzi-lo à natureza (estrutura biológica), tampouco a fenômenos linguísticos. Assim, o corpo pode ser visto como fluido, excessivo e transgressivo, na medida em que rompe seus limites e especificidades histórico-culturais (Willians, 1998).

Concordo também com Ortega $(2008,2007)$ quando diz que o corpo não desaparece no ciberespaço ${ }^{21}$. Nesse sentido, apesar de a internet possibilitar a produção de novas 'imagens' corporais e posicionamentos identitários, é importante reconhecer que o usuário continua 'tendo/sendo' um corpo e que as narrativas (online) são também produto/efeito de 'sensações' corporais. Entretanto, talvez o corpo não seja apenas redefinido ou transformado virtualmente, mas constituído ou produzido 'diferentemente' e de forma contínua pela interação com o computador (e outros corpos e máquinas). Nesta direção, para além de dicotomias tradicionais (mente-corpo, masculino-feminino, natureza-cultura, experiência-discurso), Elizabeth Grosz (2000) destaca que os corpos são irredutíveis ao sexo (natureza), ainda que sejam sexualmente específicos, como também são mutuamente constitutivos ou "necessariamente entrelaçados a particularidades raciais, culturais e de classe" (Grosz, 2000, p.79). Por conseguinte, o modelo ideal de corpo (humano) deve ser desafiado pela afirmação de uma multiplicidade de corpos distintos, de um campo de 'diferença'.

De outro ponto de vista, torna-se interessante citar a feminista Donna Haraway, para a qual seríamos todos ciborgues, híbridos de máquina e organismo. A imagem do ciborgue significa a própria confusão de fronteiras, bem como ambiguidades criativas. Segundo Haraway (2000, p.40), estas criaturas híbridas habitam "mundos" que são 'simultaneamente' naturais e fabricados. Esta discussão 'pós-humanista' é oportuna para redimensionar ou colocar em novos termos algumas cisões ou dicotomias tradicionais, como é o caso da relação entre humanos e máquinas, sem, contudo, rejeitar a 'materialidade' e 'experiência subjetiva do corpo' (Ortega, 2008).

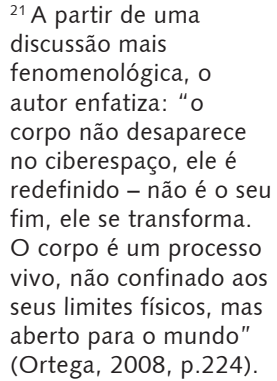

\section{Referências}

AUGÉ, M. Não-lugares: introdução a uma antropologia da supermodernidade. Campinas: Papirus, 1994.

BAKHTIN, M. Speech genres \& other late essays. Austin: University of Texas Press, 1999.

BATAILLE, G. O erotismo. São Paulo: Arx, 2004.

BENOTSCH, E.G.; KALICHMAN, S.; CAGE, M. Men who have sex partners via the internet: prevalence, predictors, and implications for HIV prevention. Arch. Sex. Behav., v.31, n.2, p.177-83, 2002.

BROWN, G.; MAYCOCK, B.; BURNS, S. Your picture is your bait: use and meaning of cyberspace among gay men. J. Sex Res., v.42, n.1, p.63-73, 2005.

BULL S.S.; MCFARLANE, M.; RIETMEIJER, C. HIV and sexually transmitted infection risk behaviors among men seeking sex with men on-line. Am. J. Public Health, v.91, n.6, p.988-9, 2001.

BUTLER, J. Problemas de gênero: feminismo e subversão da identidade. Rio de Janeiro: Civilização Brasileira, 2003. 
CROSSLEY, M.L. The perils of health promotion and the 'barebacking' backlash. Health, v.6, n.1, p.47-68, 2002.

DA MATA, R. O ofício de etnólogo, ou como ter "anthropological blues". In: NUNES, E.O. (Org.). A aventura sociológica: objetividade, paixão, improviso e método na pesquisa social. Rio de Janeiro: Zahar, 1978. p.23-35.

ELFORD, J. Changing patterns of sexual behaviour in the era of highly active antiretroviral therapy. Curr. Opin. Infect. Dis., v.19, n.1, p.26-32, 2006.

GAUTHIER, D.; FORSYTH, C.J. Bareback sex, bug chasers, and the gift of death. Deviant Behav., v.20, n.1, p.85-100, 1999.

GEERTZ, C. A interpretação das culturas. Rio de Janeiro: LTC, 1989.

GERGEN, K.J. An invitation to social construction. London: Sage Publications, 1999.

GROSZ, E. Corpos reconfigurados. Cad. Pagu, v.14, n.1, p.45-86, 2000.

GROV, C. Barebacking websites: electronic environments for reducing or inducing HIV risk. AIDS Care, v.18, n.8, p.990-7, 2006.

GROV, C.; PARSONS, J.T. Bug chasing and gift giving: the potential for HIV transmission among barebackers on the internet. AIDS Educ. Prev., v.18, n.6, p.490-503, 2006.

HALKITIS, P.N.; PARSONS, J.T. Intentional unsafe sex (barebacking) among HIV-positive gay men who seek sexual partners on the internet. AIDS Care, v.15, n.3, p. 367-78, 2003.

HALKITIS, P.N.; PARSONS, J.T.; WILTON, L. Barebacking among gay and bisexual men in New York city: explanations for the emergence of intentional unsafe behavior. Arch. Sex. Behav., v.32, n.4, p.351-7, 2003.

HARAWAY, D. Manifesto ciborgue: ciência, tecnologia e feminismo-socialista no final do século XX. In: SILVA, T.T. (Org.). Antropologia do ciborgue: as vertigens do pós-humano. Belo Horizonte: Autêntica, 2000. p.37-129.

HUEBNER, D.M.; PROESCHOLDBELL, R.J.; NEMEROFF, C.J. Do gay and bisexual men share researchers' definitions of barebacking? J. Psychol. Hum. Sex., v.18, n.1, p.67-77, 2006.

LE BRETON, D. Adeus ao corpo. In: NOVAES, A. (Org.). O homem-máquina: a ciência manipula o corpo. São Paulo: Companhia das Letras, 2003. p.123-37.

LÉOBON, A.; FRIGAULT, L-R. La sexualité bareback: d'une culture de sexe à la réalité des prises de risque. 2005. Disponível em: <http://www.gaystudies.org/article_leobon_ bareback.pdf>. Acesso em: 20 out. 2006.

LÉVY, J.; GARNIER, C.; THOER-FABRE, C. Du viagra à internet: technologisation de la sexualité et enjeux politiques. Bull. Hist. Pol., v.15, n.1, p.25-35, 2006.

LÉVY, P. Cibercultura. São Paulo: Editora 34, 1999.

LUPTON, D. Risk. London: Routledge, 1999.

. The emotional self. London: Sage Publications, 1998.

MANSERGH, G. et. al. 'Barebacking' in a diverse sample of men who have sex with men. AIDS, v.16, n.4, p.653-9, 2002.

MILLER, D.; SLATER, D. Etnografia on e off-line: cibercafés em Trinidad. Horiz. Antropol., v.10, n.21, p.41-65, 2004.

MORAIS, C.M.; ROCHA, D.L. Porque existe tanto brasileiro no orkut? Ou as redes sociais e o homem cordial. 2005. Disponível em: <http://www.intercom.org.br/papers/ nacionais/2005/resumos/R1612-1.pdf>. Acesso em: 20 ago. 2007.

ORTEGA, F. O corpo incerto: corporeidade, tecnologias médicas e cultura contemporânea. Rio de Janeiro: Garamond, 2008. 
ORTEGA, F. Corporeidade e biotecnologias: uma crítica fenomenológica da construção do corpo pelo construtivismo e pela tecnobiomedicina. Cienc. Saude Colet., v.12, n.2, p.381-8, 2007.

PARSONS, J. et al. Sexual harm reduction practices of HIV-seropositive gay and bisexual men : serosorting, strategic positioning, and withdrawal before ejaculation. AIDS, v.19, suppl.1, p.S13-S25, 2005.

POTTER, J. Representing reality: discourse, rhetoric and social construction. London: Sage Publications, 1997.

ROFES, E. Desires as defiance: gay male sexual subjectivities and resistance to sexual health promotion. Health Educ. J., v.61, n.2, p.125-37, 2002.

ROSS, M.W. Typing, doing, and being: sexuality and the internet. J. Sex Res., v.42, n.4, p.342-52, 2005.

RUBIN, G. Thinking sex: notes for a radical theory of the politics of sexuality. In: VANCE, C.S. (Org.). Pleasure and danger: exploring female sexuality. Boston: Routledge \& Kegan Paul, 1984. p.267-319.

SEMERENE, B. Abrindo as portas dos salões virtuais. In: PORTO, S.D. (Org.). Sexo, afeto e era tecnológica: um estudo de chats na internet. Brasília: Ed. Universidade de Brasília, 1999. p.29-40.

SHERNOFF, M. Condomless sex: gay men, barebacking, and harm reduction. Soc. Work, v.51, n.2, p.106-13, 2006.

The sociology of barebacking. Gay Lesbian Rev., v.12, n.1, p.33-35, 2005.

SHILLING, C.; MELLOR, P.A. Embodiment, structuration theory and modernity: mind/body dualism and the repression of sensuality. Body Soc., v.2, n.4, p.1-15, 1996.

SILVA, L.A.V. Barebacking e a possibilidade de soroconversão. Cad. Saude Publica, v.25, n.6, p.1381-9, 2009.

Desejo à flor da tel@: a relação entre risco e prazer nas práticas de barebacking. 2008. Tese (Doutorado) - Instituto de Saúde Coletiva, Universidade Federal da Bahia, Salvador. 2008.

SLATER, D. Making things real: ethics and order on the internet. Theory Cult. Soc., v.19, n.5/6, p.227-45, 2002.

SPINK, M.J.P.; MEDRADO, B. Produção de sentidos no cotidiano: uma abordagem teórico-metodológica para análise das práticas discursivas. In: SPINK, M.J.P. (Org.). Práticas discursivas e produção de sentidos no cotidiano: aproximações teóricas e metodológicas. São Paulo: Cortez, 1999. p.41-61.

SUAREZ, T.; MILLER J. Negotiating risks in context: a perspective on unprotected anal intercourse and barebacking among men who have sex with men - where do we go from here? Arch. Sex. Behav., v.30, n.3, p.287-300, 2001.

TEWKSBURY, R. Bareback sex and the quest for HIV: assessing the relationship in internet personal advertisements of men who have sex with men. Deviant Behav., v.24, n.5,

TURKLE, S. Cyberspace and identity. Contemp. Sociol., v.28, n.6, p.643-8, 1999.p.46782, 2003.

WILLIAMS, S.J. Bodily dys-order, excess and the transgression of corporeal boundaries. Body Society., v.4, n.2, p.59-82, 1998.

WOLITSKI, R.J. The emergence of barebacking among gay and bisexual men in the United States: a public health perspective. J. Gay Lesbian Psychother., v.9, n.3/4, p.9-34, 2005.

YEP, G.A.; LOVAAS, K.E.; PAGONIS, A.V. The case of "riding bareback": sexual practices and the paradoxes of identity in the era of Aids. J. Homosex., v.42, n.4, p.1-14, 2002. 
SILVA, L.A.V. La ciber-sexualidad y la investigación online: algunas reflexiones sobre el concepto barebacking. Interface - Comunic., Saude, Educ., v.14, n.34, p.513-27, jul./set. 2010.

Este artículo es resultado de una investigación online sobre aspectos de la sexualidad masculina, más precisamente sobre las inter-acciones masculinas en nuevos contextos de la epidemia de HIV/Sida. Trata de discutir las posibilidades de la internet como campo de investigación, considerando los aspectos socio-culturales abiertos por las nuevas tecnologías de la información. Este es el caso de las prácticas de barebacking generalmente definido como sexo anal desprotegido de forma intencionada. Más específicamente en este artículo se plantearán algunas tensiones y ambiguidad conceptuales del barebacking, principalmente en lo que se refiere al sexo desprotegido entre parejas fijas y entre parejas ocasionales, de acuerdo con la discusión expuesta por algunos usuarios de las comunidades del orkut en el contexto brasileño. Finalmente se destaca que los actores que se dicen barebackers no son necesariamente los mismos, ni entienden el concepto de la misma forma; lo cual exige una reflexión más amplia sobre sus distintos usuarios y conceptos de uso.

Palabras clave: Internet. Sexualidad. Homossexualidad masculina. Sexo inseguro. Síndrome de Inmunodeficiência Adquirida. VIH. 
